\title{
Ovarian cancer stem-like side-population cells are tumourigenic and chemoresistant
}

\author{
L Hu', C McArthur ${ }^{2}$ and RB Jaffe ${ }^{*, I}$ \\ 'Center for Reproductive Sciences, Department of Obstetrics, Gynecology and Reproductive Sciences, University of California, San Francisco, \\ CA 94 I43-0556, USA; '2Sandler Sorting Facility, Department of Medicine, University of California, San Francisco, CA 94 I43-0556, USA
}

BACKGROUND: Ovarian cancer is the most lethal gynaecological malignancy. Although ovarian cancer patients often respond initially to chemotherapy, they usually develop chemoresistance. We hypothesised that a small portion of ovarian cancer cells have stem-like cell properties that contribute to tumourigenesis and drug resistance.

METHODS: Flow cytometry and Hoechst 33342 efflux isolated side-population (SP) cells from ascites derived from ovarian cancer patients and from mice inoculated with human ovarian cancer cell lines. The SP cells were examined for stem cell markers OCT4, NANOG, STELLAR, and ABCG2/BCRPI by immunocytochemistry and RT-PCR. The SP cells and non-SP cells were studied for tumourigenesis and chemoresistance in vitro and in vivo.

RESULTS: The SP cells expressed ABCG2/BCRPI, OCT4, STELLAR, and NANOG, detected by immunocytochemistry and RT-PCR. ABCG2/BCRPI expression was higher in SP than in non-SP cells. Xenogeneic mice inoculated with SP cells yielded more tumours than did mice inoculated with non-SP cells. In parallel, SP cell culture resulted in extensive cell proliferation, which was markedly more than in non-SP cells. SP cells resisted chemotherapy compared with non-SP cells, both in vivo and in vitro.

CONCLUSION: Ovarian cancer SP cells are tumourigenic and chemoresistant. ABCG2/BCRPI has an important role in chemoresistance, which has implications for new therapeutic approaches.

British Journal of Cancer (2010) I 02, 1276- 1283. doi:I0.1038/sj.bjc.6605626 www.bjcancer.com

Published online 30 March 2010

(c) 2010 Cancer Research UK

Keywords: side population; ovarian cancer stem-like cells; tumourigenesis; drug resistance; ABCG2

The majority of ovarian cancer patients with advanced disease eventually develop chemotherapy resistance. The concept of cancer stem-like cells in solid tumours opens new approaches to carcinogenesis and chemotherapy. Cancer stem-like cells share many properties with normal stem cells: they have a protracted lifespan, relative quiescence, ability for self-renewal, the capacity to induce tumourigenesis, and resistance to chemotherapeutic agents and apoptosis (Reya et al, 2001; Beachy et al, 2004; Sales et al, 2007; Wu et al, 2007).

Surface markers expressed on cancer stem-like cells can be used to isolate these cells. However, these markers differ in different types of tumours. The capacity to extrude Hoechst dye, one of the stem cell characteristics, has also been used to identify cancer stem-like cells (Dean et al, 2005). These cells express drug transporters that make them resistant to many chemotherapeutic agents (Allikmets et al, 1998a; Dean et al, 2005). ABCG2/BCRP1 (breast cancer-resistance protein-1), an ATP-binding cassette (ABC) transporter, is a cell surface drug-resistance marker as well, which has been used to identify stem cells from a variety of tissues, including tumours (Zhou et al, 2001b; Diestra et al, 2002a). ABCG2/BCRP1 expression confers resistance to chemotherapeutic agents and permits cells to exclude Hoechst dye 33342 (Molecular

* Correspondence: Dr RB Jaffe; E-mail: jaffer@obgyn.ucsf.edu Received 18 December 2009; revised 26 February 2010; accepted 4 March 2010; published online 30 March 2010
Probes, Eugene, OR, USA) (Allikmets et al, 1998a; Dean et al, 2005). This dye-excluding side-population (SP) phenotype has been used in various tissues to select presumptive stem-like cells. Side-population cells are enriched with cancer stem-like cells in a variety of carcinomas (Kondo et al, 2004a; Hirschmann-Jax et al, 2005; Haraguchi et al, 2006; Ho et al, 2007; Wang et al, 2007). These cells have been found in several tissues and cell lines, including bone marrow, skin, lung, mammary epithelium, and embryonic stem cells (Alvi et al, 2003; Nishimura et al, 2003; Majka et al, 2005; Yano et al, 2005). They have been isolated from malignancies, including leukaemia (Feuring-Buske and Hogge, 2001; Wulf et al, 2001) and breast (Doyle and Ross, 2003), brain (Hirschmann-Jax et al, 2005), prostate (Hirschmann-Jax et al, 2005), retinoblastoma (Seigel et al, 2005), lung (Giangreco et al, 2004), and ovarian (Patrawala et al, 2005; Szotek et al, 2006) cancers.

The SP phenotype, coupled with the expression of stem cell markers, is the hallmark of normal stem cells and cancer stem-like cells as well (Zhou et al, 2001b; Scharenberg et al, 2002; Diestra et al, 2002a; Dean et al, 2005).

We explored the tenet that SP cells isolated from human ovarian cancer cells by Hoechst dye exclusion after flow cytometry show stem cell characteristics. The SP cells were examined for the drug-resistance transporter, ABCG2/BCRP1, and for other stem cell markers, OCT4, NANOG, and STELLAR, by immunocytochemistry and RT - PCR. The SP and non-SP cells were studied for tumourigenesis and chemoresistance in vitro and in vivo. 


\section{MATERIALS AND METHODS}

\section{Materials}

The ABCG2/BCRP1 monoclonal antibody (BXP-21) was from Sigma Chemicals (St Louis, MO, USA). The OCT 4 monoclonal antibody was from Chemicon (Tarrytown, NY, USA). NANOG and STELLAR polyclonal antibodies were kindly provided by $\mathrm{Dr} A$. Clark (University of California, San Francisco (UCSF)). Cisplatin was from Sigma Aldrich (St Louis, MO, USA). The human OVCAR3 cell line was a gift from Dr T. Hamilton (Fox Chase Cancer Center, Philadelphia, PA, USA), and the ovarian cancer cisplatin-resistant cell line, A2780-CP, was a gift from Dr J. Chan (UCSF). All other cell lines were from the UCSF Gynecologic Ovarian Tissue Bank. Culture reagents were obtained from the Cell Culture Facility, UCSF.

\section{Human ovarian cancer ascites}

Primary ovarian cancer cells were collected from stage III fresh ovarian cancer patient ascites at laparotomy through the UCSF Gynecologic Ovarian Tissue Bank. Ascite fluid was collected and was placed in a refrigerator at $4{ }^{\circ} \mathrm{C}$ for $1-2 \mathrm{~h}$. After discarding the supernatant, cells were resuspended in medium (RPMI-1640) and centrifuged to isolate the cellular components. The cells were then cultured with medium RPMI-1640 supplemented with $2.0 \mathrm{gl}^{-1}$ glucose and $0.3 \mathrm{gl}^{-1} \mathrm{~L}$-glutamine, as well as with $10 \%$ fetal bovine serum (FBS), $1 \%$ penicillin/streptomycin, and $1 \%$ fungizone and incubated at $37^{\circ} \mathrm{C}$. Cells were analysed within 7 days, during which sorting of SP cells by flow cytometry, RT - PCR, and immunoassay was performed.

\section{Experimental animals}

Female athymic immunodeficient mice (Simonsen Laboratories, Gilroy, CA, USA) were delivered to the UCSF Laboratory Animal Resource Center, and were housed in isolated conditions, fed autoclaved standard pellets and water, and allowed to adapt to their new environment. All protocols involving immunodeficient mice were approved by the Committee on Animal Research, UCSF.

\section{Mouse ovarian cancer ascites}

Mouse ascites were collected from female athymic nude mice (5-7 weeks old) inoculated i.p. with human OVCAR3 cells for 6 weeks. Cells were analysed within 7 days with sorting of SP cells by flow cytometry, and RT-PCR and immunoassay were performed as described in the human ovarian cancer ascites section.

\section{Identification of SP cells}

Identification of SP cells was performed as described previously by Goodell (2002). Cells were incubated with $5 \mu \mathrm{g} \mathrm{ml}^{-1}$ Hoechst 33342 dye (Molecular Probes) for $90 \mathrm{~min}$ with and without $50 \mu \mathrm{M}$ verapamil. Cell samples were analysed and sorted using a Moflo MLS cell sorter (Beckman-Coulter, Inc., Hialeah, FL, USA) with UV capabilities and SUMMIT software for data acquisition and analysis. An argon laser was used to excite the Hoechst dye. Fluorescence emission was collected with a $405 / 30 \mathrm{~nm}$ bandpass filter for Hoechst blue and a 670/40 nm bandpass filter for Hoechst red. Dead cells were excluded by propidium iodide fluorescence at $670 / 30 \mathrm{~nm}$.

\section{Kidney capsule graft}

Side population cells or non-SP cells (500 cells each) were isolated from ascites derived from mice inoculated with the human ovarian cancer cell line, OVCAR3, or from ascites derived from ovarian cancer patients, suspended in $50 \mu \mathrm{l}$ of rat tail collagen gel as previously described (Hayward et al, 2001) and grafted under the kidney capsule of female athymic mouse hosts. The hosts were killed after 8 weeks of growth and the kidneys with grafts were explanted, fixed in formalin, and embedded in paraffin.

\section{Intraperitoneal inoculation of SP cells}

Two groups of nude mice $(n=12)$ were inoculated separately i.p. with SP cells $v s$ non-SP cells (20000 cells each) from A2780-CP (cisplatin-resistant human ovarian cancer cell line). At 8 weeks after inoculation, the mice were killed and tumour burden was quantified. In a separate experiment, four groups of nude mice (5-7 weeks old, $n=16$ ) were inoculated i.p. with SP $v s$ non-SP cells (20000 cells) from A2780-CP. At 2 weeks after inoculation, two groups (SP $(n=4)$ vs non-SP cells $(n=4))$ were treated with cisplatin $\left(10 \mathrm{mg} \mathrm{kg}^{-1}\right.$ B.W.) 3 times weekly for 3 weeks. Two additional groups (SP $(n=4)$ vs non-SP cells $(n=4)$ ) received vehicle alone.

SP culture Side population cells and non-SP live cells (500 cells each) obtained from ascites derived from ovarian cancer patients were seeded on 24-well plastic culture plates. Cells were cultured in RPMI-1640 containing $10 \% \mathrm{FBS}, 100$ units $\mathrm{ml}^{-1}$ penicillin, and $100 \mu \mathrm{g} \mathrm{ml}^{-1}$ streptomycin. Cultures were incubated at $37^{\circ} \mathrm{C}$ in a humidified atmosphere of $95 \% \mathrm{O}_{2}$ and $5 \% \mathrm{CO}_{2}$. The medium was changed every other day. The morphological appearance of cells was captured at the end of the fifth day of culture. At least ten $\times 150$ microscopic fields were scored.

Reverse transcription-polymerase chain reaction (RT-PCR) Total RNA was extracted from pellets of human ovarian cancer cells from ascites derived from patients and mice bearing human OVCAR3 cells using an RNeasy minikit (Qiagen, Hiden, Germany) according to the manufacturer's protocol. Reverse transcriptionpolymerase chain reaction was then performed using a OneStep RT - PCR Kit (Qiagen). The primers used for PCR amplification were BCRP1 (231 bp): 5' -CAACCATTGCATCTTGGCTG-3' and 5'-CA AGGCCACGTGATTCTTCC-3'; STELLAR (174bp): $5^{\prime}$-GTTACTGGG CGGAGTTCGTA- $3^{\prime}$ and $5^{\prime}$-TGAAGTGGCTTGGTGTCTTG-3' ${ }^{\prime}$. Conditions for both BCRP1 and STELLAR were $95^{\circ} \mathrm{C}$ for $1 \mathrm{~min}, 58^{\circ} \mathrm{C}$ for $1 \mathrm{~min}$, and $72{ }^{\circ} \mathrm{C}$ for $2 \mathrm{~min}$, for 40 cycles. Acquired DNA samples were loaded onto a $2 \%$ agarose gel and analysed.

Fluorescent immunostaining in suspension Patient ovarian cancer cells or OVCAR3 cells were double labelled in suspension with Hoechst 33342, and with either ABCG2/BCRP1 or OCT4. Cells $\left(2 \times 10^{6}\right)$ were centrifuged at 800 r.p.m. for $5 \mathrm{~min}$. The supernatant was decanted and cells were resuspended in $4 \mathrm{ml}$ RPMI with $10 \%$ fetal calf serum. Hoechst 33342 dye (Molecular Probes) was added at $5 \mu \mathrm{g} \mathrm{ml}^{-1}$, and cells were incubated at $37^{\circ} \mathrm{C}$ for $90 \mathrm{~min}$. Cells were washed twice in PBS and centrifuged for $5 \mathrm{~min}$. Cells were resuspended in PBS and then received 1:200 ABCG2/BCRP1 antibody or OCT 4 antibody and were incubated for $1 \mathrm{~h}$ at room temperature. Cells were washed twice with PBS and resuspended. TRITC-conjugated anti-mouse IgG (Sigma Chemicals) was added at $1: 100$ dilution. Cells were incubated for $1 \mathrm{~h}$ at room temperature. After washing twice with PBS, cells were resuspended and pipetted onto a slide and covered with a coverslip for microscopic viewing.

Immunofluorescent analysis of SP cells Side population cells were sorted directly onto poly-L-lysine-coated slides, then air-dried and fixed in 50:50 methanol/acetone for $5 \mathrm{~min}$ as described by Alvi et al (2003). The cells were pretreated with $3 \%$ horse serum in PBS plus $0.05 \%$ Tween-20 for $1 \mathrm{~h}$, and then rinsed in PBS and incubated with both 1:500 rabbit anti-NANOG antibody and $1: 200$ mouse anti-ABCG2/BCRP1 antibody for $1 \mathrm{~h}$. The cells were thoroughly washed in PBS before application of $1: 200$ of both 
FITC-conjugated anti-rabbit IgG and TRITC-conjugated antimouse IgG, and finally washed again in PBS. A similar procedure was used for staining CD34 1:200 with mouse anti-CD34 antibody and for staining CD44 1:200 with mouse anti-CD44 antibody.

Immunofluorescence in tumour tissues The ovarian cancer tissue from mice inoculated with OVCAR3 cells was washed extensively in PBS. Before immunostaining, tissues were pretreated with $3 \%$ horse serum in PBS plus $0.05 \%$ Tween-20 for $1 \mathrm{~h}$. Tissues were rinsed in PBS and incubated with both 1:500 rabbit anti-NANOG antibody and 1:200 mouse anti-ABCG2/BCRP1 antibody for $16 \mathrm{~h}$ on an orbital shaker at $4{ }^{\circ} \mathrm{C}$. Tissues were washed thoroughly in PBS before application of $1: 200$ of both FITC-conjugated antirabbit IgG and TRITC-conjugated anti-mouse IgG, and finally washed again in PBS. Immunostained tissues were examined by microscopy.

Apoptosis assessment Side population cells $v s$ non-SP cells were seeded (5000 cells) on eight-well glass culture slides. Cells were cultured in RPMI-1640 for $24 \mathrm{~h}$. The medium was then removed and replaced with culture medium in four individual wells for SP cells $v s$ non-SP cells: (1) vehicle, (2) cisplatin $5 \mu \mathrm{M}$, (3) verapamil $50 \mu \mathrm{M}$, and (4) cisplatin plus verapamil, for an additional $48 \mathrm{~h}$. After fixing with $2 \%$ paraformaldehyde, cells were used to assess apoptosis. DNA labelling with digoxigenin dUTP and terminal transferase, followed by immunocytochemical staining with peroxidase-coupled antidigoxigenin antibody and diaminobenzidine, was carried out with the reagents supplied in the Apoptag kit (Intergen, Purchase, NY, USA). After light counterstaining with haematoxylin, nuclei that stained brown were scored as positive for apoptosis and those that stained blue were scored as negative. At least ten $\times 150$ microscopic fields were scored, and the apoptotic index was calculated as the percentage of cells that were scored positive.

Light microscopy and analysis Ovarian cancer tissue and cells immunostained with ABCG2/BCRP1, OCT4, and NANOG were examined with a Leica DMRB or Leica (Allendale, NJ, USA) Ortholux II photomicroscope at low and high magnification.Images were collected with a Photonics (Fukuoka, Japan) DEI-470 CCD camera and a RasterOps (Santa Clara, CA, USA) 24X LTV frame grabber, imported directly into Adobe Photoshop (San Jose, CA, USA). Photomicrographic plates were composed from the original data in Photoshop without alteration or manipulation.

Statistics Data were analysed using the unpaired Student's $t$-test for comparison between groups. Differences between groups were considered statistically significant at $P<0.05$. Experiments in vivo were performed in duplicate, whereas experiments in vitro were performed in triplicate.

\section{RESULTS}

\section{Ovarian cancer SP cells}

Figure 1 shows two representative experiments from flow cytometry. Panel A shows a small number of cells $(1.65 \%)$ in the box R4 from the SP from OVCAR3 cells. The SP was blocked by $88 \%$ by $50 \mu \mathrm{m}$ verapamil. Panel B illustrates a small number of cells
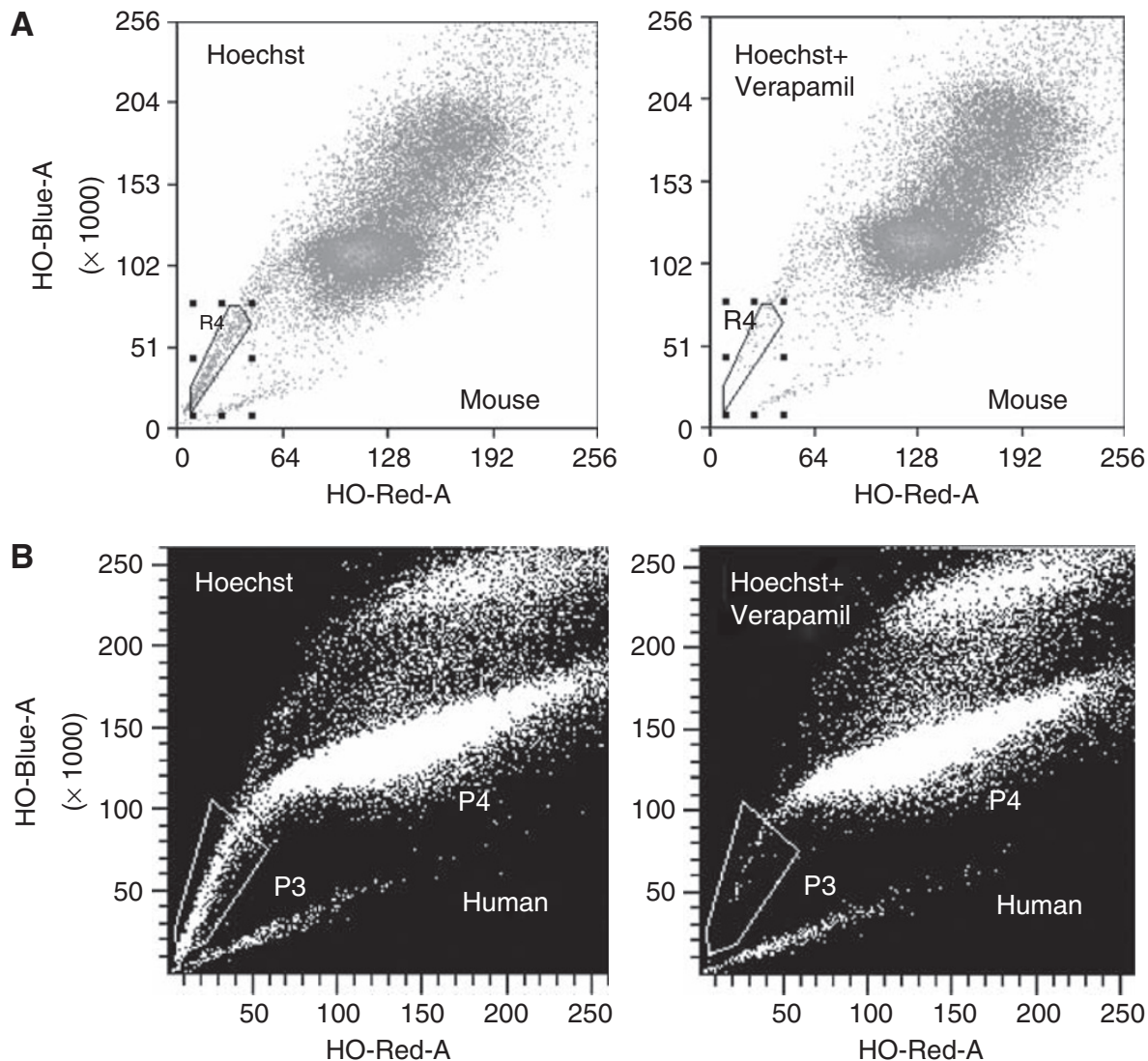

Figure I (A) Side population (SP) of human OVCAR3 ovarian cancer cells from mouse ascites detected by flow cytometry. Boxed cells (labelled R4) indicate Hoechst-excluding SP. (B) SP of patient ascites-derived ovarian cancer cells detected by flow cytometry. Boxed cells (labelled P3) indicate Hoechstexcluding SP. Addition of $50 \mu \mathrm{M}$ verapamil resulted in a marked reduction in SP in $\mathbf{A}$ and $\mathbf{B}$ 
$(0.3 \%)$ in the box P3 from the SP from human ovarian cancer cells. The SP was blocked $80 \%$ by $50 \mu \mathrm{M}$ verapamil.

The mean percentage of SP cells from ascites derived from human ovarian cancer patients, ascites from mice inoculated with OVCAR3, and A2780-CP cell lines were $0.4 \pm 0.05 \%, 1.01 \pm 0.27 \%$, and $0.45 \pm 0.05 \%$, respectively. We also sorted SP cells from other human ovarian cancer cell lines, including A2780, HEYA8, OCC1, and SKOV3. Percentages from these cell lines ranged from 0.1 to 2.4\%, (A2780: 0.2\%; HEYA8: 2.4\%; OCC1: 0.1\%; and SKOV3: $1.7 \%$ ).

OCT4 and ABCG2/BCRP1 immunopositive cells colocalise with Hoechst-dim cells in OVCAR3 cells

Staining of OCT4-immunopositive OVCAR3 cells was detected in Hoechst-dim cells, further suggesting a stem cell phenotype (Figure 2A-D). OVCAR3 cells that were Hoechst-dim (Figure 2B) were OCT4-bright (Figure 2C), as seen more definitively in the merged image (Figure 2D). Bright-field images were captured (Figure 2A) to ensure that labelled cells appeared intact.

Figure $2 \mathrm{E}-\mathrm{H}$ shows that $\mathrm{ABCG} / \mathrm{BCRP} 1$ confers the ability to exclude Hoechst dye. OVCAR3 cells immunoreactive for ABCG2/ BCRP1 were Hoechst-dim (Figure 2F and G). OVCAR3 cells that were ABCG2/BCRP1-bright were Hoechst-dim, as seen in the merged image (Figure $2 \mathrm{H}$ ). Bright-field images were captured (Figure 2E). These findings show that ABCG2/BCRP1 colocalises with Hoechst-dim cells.

Immunoreactivity of stem cell markers in sub-populations of OVCAR3 cells

The SP phenotype is thought to occur through action of the ABCG2/BCRP1 transport cassette protein (Zhou et al, 2001a;
Ahmed-Belkacem et al, 2006). To analyse whether SP cells coexpressed stem cell markers ABCG2/BCRP1 and NANOG, we examined their immunological activity. We found that SP cells stained strongly with ABCG2/BCRP1 antibody (Figure 2I), and that SP cells also costained with NANOG (Figure $2 \mathrm{~K}$ ), as seen particularly in the merged image (Figure 2L). Bright-field images were captured in Figure 2J. In contrast, SP cells were not stained by CD34, a haematopoietic stem cell marker (data not shown), suggesting that the preparations were not contaminated with haematopoietic stem cells. The SP cells were not stained significantly by CD44 either (data not shown).

\section{Cancer stem cell niche}

Figure $2 \mathrm{M}-\mathrm{P}$ shows the cancer stem-like cell niches in the tumour tissue. These cells share the SP phenotype and are costained with ABCG2 and NANOG, as shown in Figure $2 \mathrm{I}-\mathrm{L}$. Figure $2 \mathrm{M}$ shows that cells stained strongly with the ABCG2/BCRP1 antibody and also costained with NANOG (Figure 2O), as seen particularly in the merged image (Figure 2P). Bright-field images are seen in Figure 2N.

\section{Chemoresistance and apoptosis}

Figure 2Q-T illustrates apoptosis of cultured SP cells from A2780$\mathrm{CP}$ after $48 \mathrm{~h}$ of treatment with cisplatin and/or verapamil in vitro. Apoptosis in SP cells in the cisplatin-treated group was $<20 \%$, indicating that SP cells were resistant to chemotherapy. However, over $95 \%$ of SP cells in the cisplatin plus verapamil-treated group were apoptotic. There were no significant apoptotic cells in control SP and verapamil-treated SP cells. The brown nuclei and debris
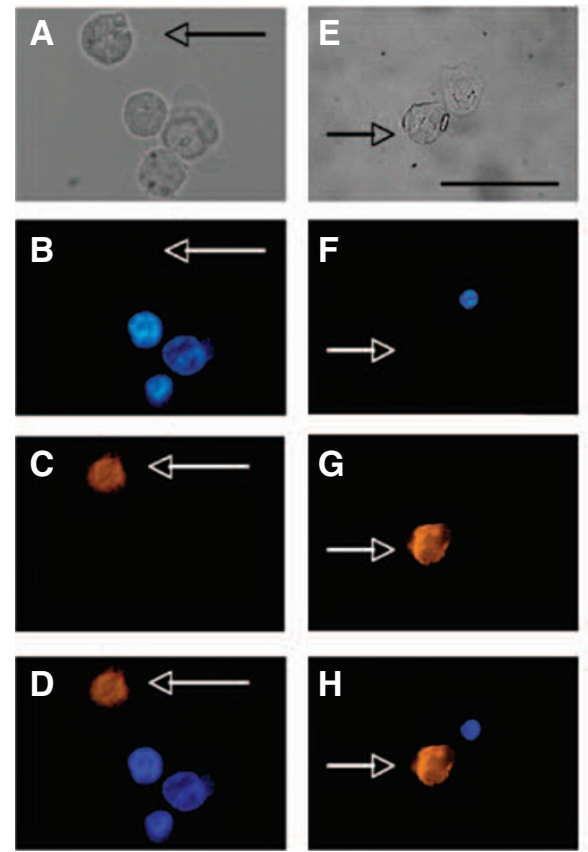
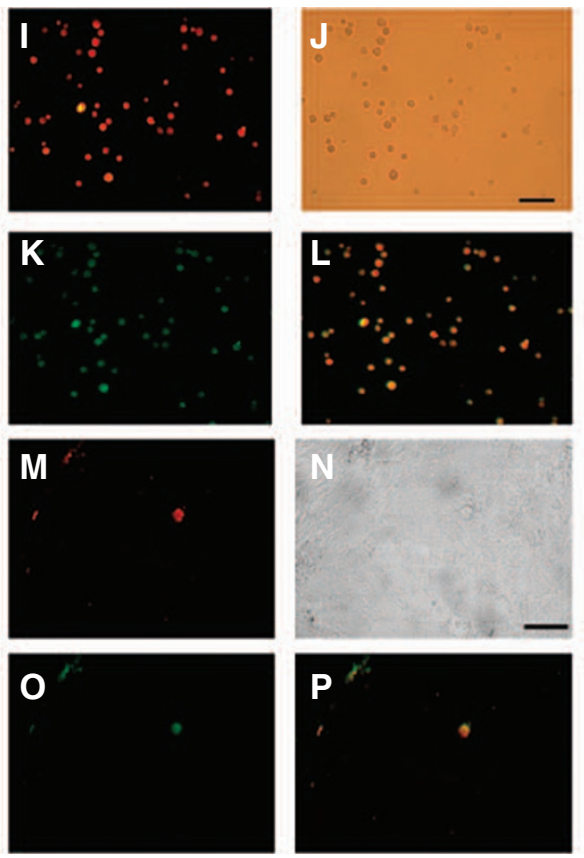

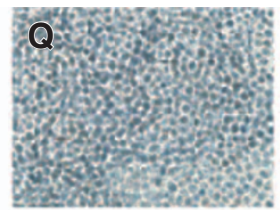

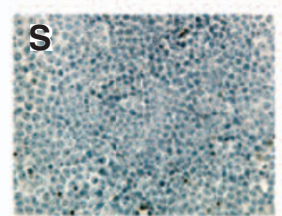
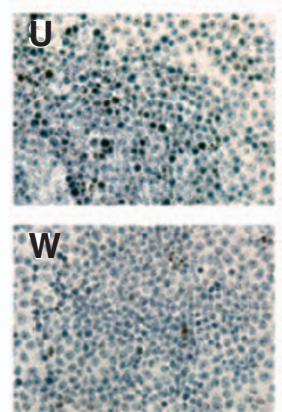
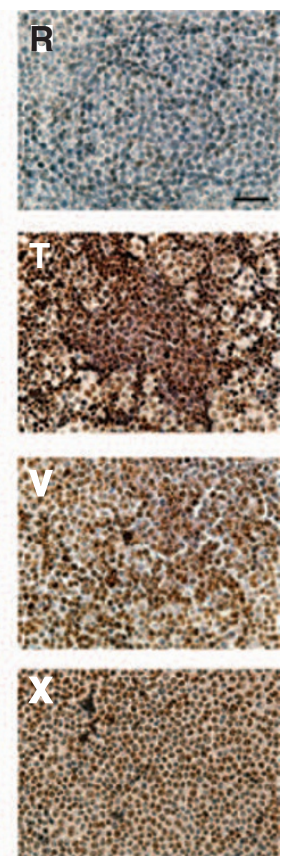

Figure 2 (A-D) Colocalisation of cells from mouse ascites bearing human ovarian cancer cells with OCT4 and Hoechst dye 33342 . (E-H) Colocalisation of cells from mouse ascites bearing human ovarian cancer cells with ABCG2/BCRPI and Hoechst dye 33342. (A, E) Bright-field; (B, F) Hoechst-dye uptake (blue); (C) OCT4 (bronze); (G) ABCG2/BCRPI (bronze); (D) merged image B and C; and (H) merged image $\mathbf{F}$ and $\mathbf{G}$. Arrows indicate the cells that are immunoreactive for OCT4 or ABCG2 and Hoechst-dim. Bar $=10 \mu \mathrm{m}$. (I-L) Immunolocalisation of ABCG2/BCRPI (red fluorescence) and NANOG (green fluorescence) in side population of human ovarian cancer cells (OVCAR3) derived from mouse ascites. (I) ABCG2/ BCRPI; (J) bright-field; (K) NANOG; (L) merged I and J. Bar $=10 \mu \mathrm{m}$. (M-P) Immunolocalisation of ABCG2/BCRPI (red fluorescence) and NANOG (green fluorescence) in mouse cancer tissues bearing human ovarian cancer cells. (M) ABCG2/BCRPI; (N) bright-field; (O) NANOG; and (P) merged $\mathbf{M}$ and $\mathbf{O}$. Arrows indicate cells that are immunoreactive for OCT4 or ABCG2. Bar $=10 \mu \mathrm{m}$. ( $\mathbf{Q}-\mathbf{X})$ SP vs non-SP cell apoptosis in vitro. Apoptosis of SP $(\mathbf{Q}-$ $\mathbf{T})$ vs non-SP cells $(\mathbf{U}-\mathbf{X})$ after 48-h treatment with cisplatin and/or verapamil in vitro. (Q, $\mathbf{Q})$ Control; $(\mathbf{R}, \mathbf{V})$ cisplatin; $(\mathbf{S}, \mathbf{W})$ verapamil; and $(\mathbf{T}, \mathbf{W})$ cisplatin plus verapamil. Brown nuclei indicate apoptotic cells. Scale bar $=10 \mu \mathrm{m}$. Note that SP cells are resistant to cisplatin $(\mathbf{R})$, but this resistance is reversed by verapamil $(\mathbf{T})$ 


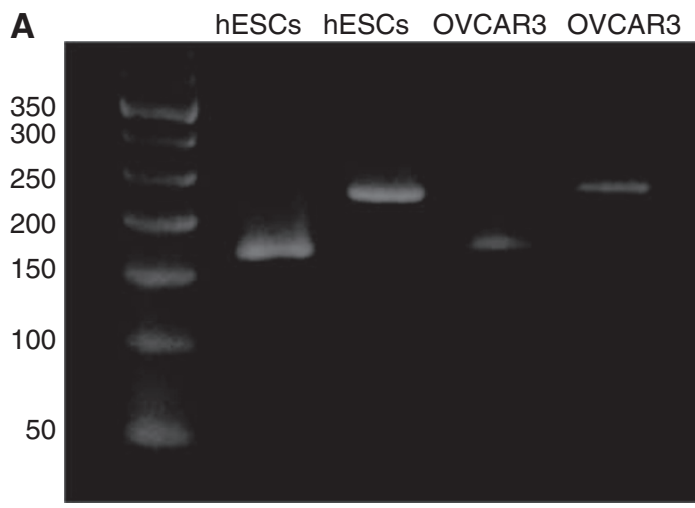

STELLAR ABCG2 STELLAR ABCG2

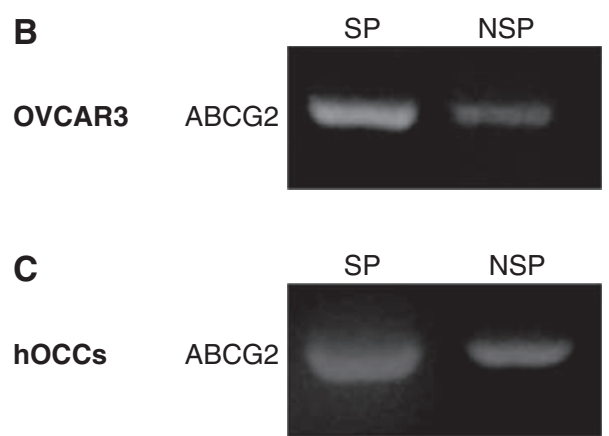

Figure 3 (A) RT-PCR analysis of $A B C G 2$ and STELLAR in mouse ascites from human ovarian cancer (OVCAR3) and human embryonic stem cells (hESCs). (B) RT-PCR analysis of ABCG2 in non-SP and SP from human ovarian cancer cells (OVCAR3). (C) RT-PCR analysis of ABCG2 in non-SP and SP cells from human ovarian cancer cells (hOCCs).

reflect cells that have undergone apoptosis. At least ten $\times 150$ microscopic fields were scored.

In a parallel study, we also showed apoptosis in cultured non-SP cells in Figure $2 \mathrm{U}-\mathrm{X}$. Apoptosis of non-SP cells in both the cisplatin-treated group and cisplatin plus verapamil-treated group was over $90 \%$ of the total cell population. However, there were no significant changes in the control and verapamil-treated groups.

\section{Gene expression}

Reverse transcriptase-PCR revealed that ABCG2/BCRP1 and STELLAR mRNA expressions were found in both human embryonic stem cells and OVCAR3 cells (Figure 3A). Because ABCG2/BCRP1, a drug-resistance transporter, is a key molecule in SP cells, ABCG2/BCRP1 mRNA was analysed in both sorted SP and non-SP cells. ABCG2/BCRP1 was expressed in SP cells more extensively than in non-SP cells (Figure 3B). ABCG2/BCRP1 expression was also found in human ovarian cancer cells from patient ascites (Figure 3C) and was expressed in SP cells more extensively than in non-SP cells.

\section{SP and tumourigenesis}

Figure 4A and $\mathrm{B}$ shows non-SP and SP live cells obtained from patient ovarian cancer ascites and cultured for 5 days. SP cells (Figure 4B) have high-density chromatin and undergo extensive proliferation (Figure 4A), whereas non-SP (Figure 4B) cells do not proliferate significantly.

Figure 4D shows tumour growth from SP cells derived from patient ovarian cancer ascites and grafted under the kidney capsule. In contrast, tumours did not develop in non-SP cells
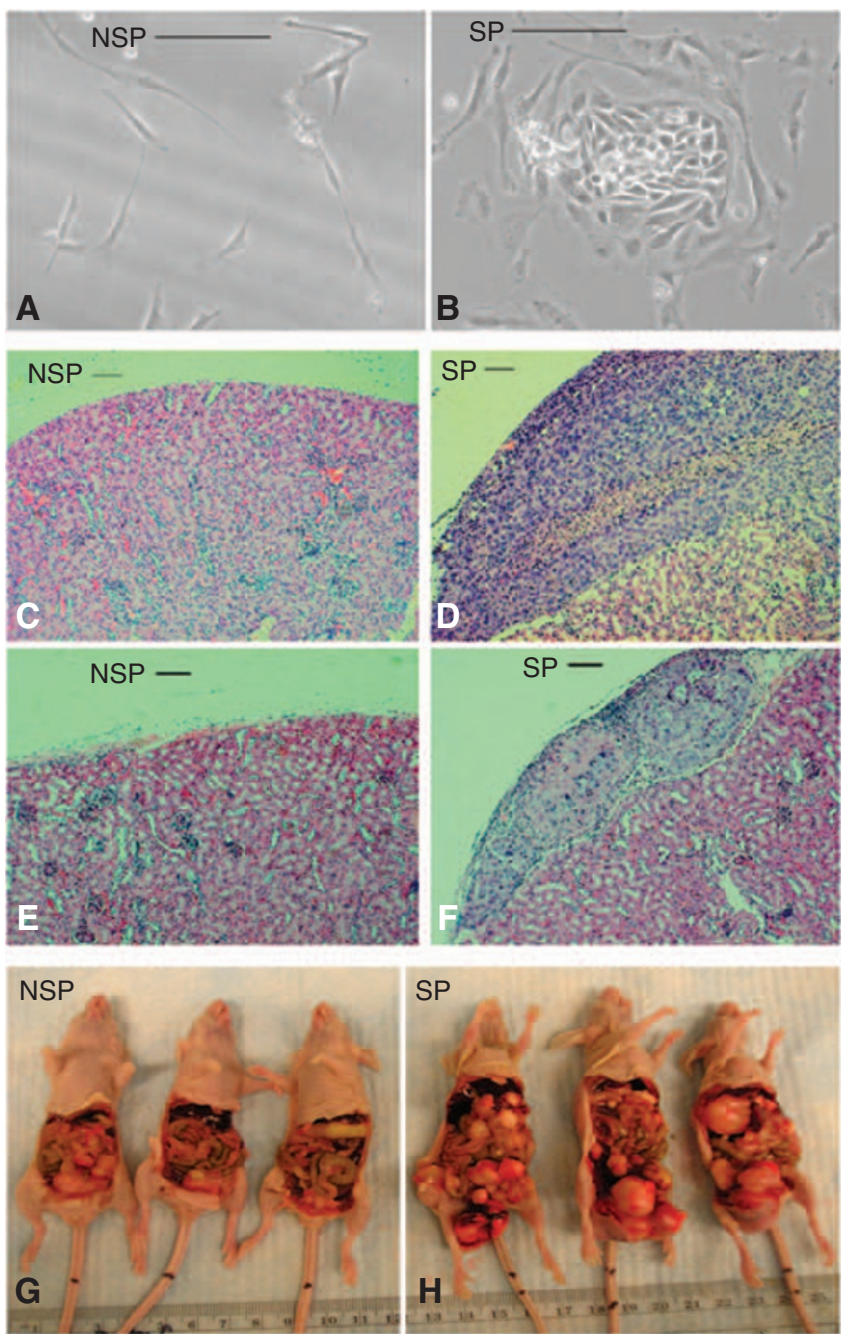

Figure 4 Non-SP cells $(\mathbf{A})$ vs SP cells $(\mathbf{B})$ from patient's ovarian cancer ascites were cultured for 5 days. Non-SP cells $(\mathbf{C})$ and SP cells (D) from human ovarian cancer cells (500 cells) derived from patient's ascites were grafted under kidney capsules in each of two mice for 8 weeks. Non-SP cells $(\mathbf{E})$ and SP cells $(\mathbf{F})$ from OVCAR3 cells (500 cells) derived from mouse model ascites were grafted under kidney capsules in each of two mice for 8 weeks. Non-SP cells (G, three mice) and SP cells $(\mathbf{H}$, three mice) from A2780-CP (cisplatin resistant) cells were injected i.p. into six mice (20000 cells per mouse) for 8 weeks. Bar $=10 \mu \mathrm{m}$.

grafted under the kidney capsule (Figure $4 \mathrm{C}$ ). Figure $4 \mathrm{~F}$ illustrates tumour growth from the SP cells derived from mice inoculated with OVCAR3 cells and grafted under the kidney capsule. In contrast, tumours did not develop in non-SP cells similarly grafted (Figure 4E).

Figure $4 \mathrm{G}$ and $\mathrm{H}$ shows tumour burden in mice after 8 weeks of inoculation with non-SP or SP cells from the A2780-CP cell line injected i.p. (three representative mice in each group). Note the extensive tumourigenesis in SP-inoculated mice compared with non-SP cell-inoculated mice. The mean tumour burden in SP-inoculated mice $(7.29 \pm 0.73)$ was significantly $(P<0.0001)$ greater $(93.85 \%)$ than that in non-SP-inoculated mice $(0.44 \pm 0.12)$.

\section{Chemoresistance in the mouse model}

The effects of cisplatin on tumour growth in nude mice $(n=16)$ are shown in Figure 5. Treatments began 2 weeks after the mice were inoculated with SP $v s$ non-SP from A2780CP cells. Tumour 


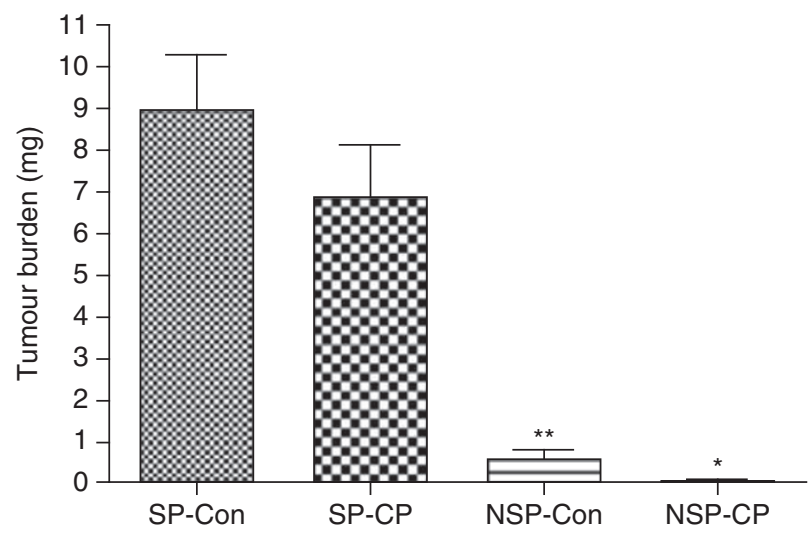

Figure 5 Effect of cisplatin on tumour burden in mice inoculated i.p. with SP vs non-SP isolated from A2780-CP cells. Treatments began 8 weeks after inoculation. Treatment groups consisted of control (vehicle) and cisplatin alone. At the end of the experiment ( 3 weeks of treatment), the mice were killed. At autopsy, tumours were excised and weighed. SP-Con $($ control $)=$ side population without treatment; SP-CP = side population with cisplatin treatment; NSP-Con = non-side population without treatment (control); NSP-CP $=$ non-side population with cisplatin treatment: $* P<0.05$ vs NSP-CP; ${ }^{*} * P<0.01$ vs SP-CON. Data are expressed as the mean (bars \pm s.d.).

burden in SP cisplatin-treated mice $(6.920 \pm 1.226 \mathrm{~g})$ was not significantly reduced $(23.08 \%)$ compared with that in SP control mice $(8.997 \pm 1.297 \mathrm{~g})$, indicating that SP cells are resistant to chemotherapy. Tumour burden in cisplatin-treated mice $(0.0325 \pm$ $0.018 \mathrm{~g})$ inoculated with non-SP cells was reduced by $94.9 \%$ $(P<0.05)$ compared with that in non-SP-inoculated control mice $(0.6426 \pm 0.23 \mathrm{~g})$. Regarding the differences in tumour burdens between SP- and non-SP-inoculated mice, tumour burden in SP control mice was greater $(92.3 \%)$ than that in the non-SP control group.

\section{DISCUSSION}

In this study, we show that SP cells have an important role in tumourigenesis and drug resistance in human ovarian cancer, both in vivo and in vitro. We identified a small SP population from ovarian cancer cells derived from ascites from patients and from nude mice inoculated with the human OVCAR3 cell line, as well as from other human ovarian cancer cell lines, including A2780, A2780-CP, HEYA8, OCC1, and SKOV3. This is consistent with findings in other tumour types (Patrawala et al, 2005; Szotek et al, 2006).

Our study indicates that ovarian cancer cells are heterogeneous. SP cells are highly proliferative compared with non-SP cells; SP xenogeneic transplant mice grew more tumours than non-SP xenogeneic transplant mice, as shown from other studies (Chiba et al, 2008; Harris et al, 2008; Steiniger et al, 2008). SP cells have characteristics of cancer stem-like cells. They have a striking capacity to proliferate, differentiate, and undergo self-renewal, enabling them to eventuate in tumour formation and repopulate tumours after therapy (Alvi et al, 2003; Kondo et al, 2004b; Hirschmann-Jax et al, 2005). This small population is likely to be responsible for tumourigenesis. Although current chemotherapy for ovarian cancer eradicates most tumour cells with high initial response rates, the majority of patients with advanced disease eventually become resistant to chemotherapy. This raises the possibility that failure to eradicate ovarian cancers may be because of failure to treat the definitive target: cancer stem-like cells. Both our in vitro and in vivo experiments show that SP cells are resistant to chemotherapy. This novel finding suggests that SP cells contribute to drug resistance and might be an attractive target for cancer therapy.

Our study shows that ovarian cancer SP cells express the embryonic stem cell markers, NANOG, OCT4, STELLAR, and ABCG2/BCRP1. OCT4 and NANOG are transcription factors in embryonic stem cells (Nichols et al, 1998; Chambers et al, 2003; Mitsui et al, 2003). Poorly differentiated tumours show overexpression of genes that are normally enriched in embryonic stem cells (Ben-Porath et al, 2008). NANOG and OCT4 are more significantly overexpressed in poorly differentiated tumours than in well-differentiated tumours (Ben-Porath et al, 2008). These genes contribute to stem cell-like phenotypes found in many tumours (Dvorak and Hampl, 2005; Wong et al, 2008). STELLAR, also known as developmental pluripotency associated-3 (DPPA3), is expressed in human embryonic cells. Particularly relevant is the expression of ABCG2/BCRP1, a calcium-sensitive cell surface protein that excludes Hoechst dye, conferring resistance to several chemotherapeutic agents (Diestra et al, 2002b; Ahmed-Belkacem et al, 2006). The ABCG2/BCRP1 gene was first isolated from human tumour cell lines, in which it was involved in drug resistance (Doyle et al, 1998; Allikmets et al, 1998b; Miyake et al, 1999). ABCG2/BCRP1 is a significant marker for Hoechst dyeextruding stem cells (Zhou et al, 2001a). Various types of ABC transporters, including proteins encoded by multidrug-resistance gene 1 (MDR1, p-glycoprotein), multidrug resistance-associated protein 1 (MRP1), as well as ABCG2/BCRP1, have been described. In bone marrow from $m d r 1 a 1 b^{-1-}$ knockout mice, a normal percentage of SP cells was obtained, suggesting that MDR1 is not correlated with the SP cells identified by Hoechst (Uchida et al, 2002). MDRI and MRP1 are not major contributors to the SP phenotype in bone marrow cells (Scharenberg et al, 2002). MDR1 (CD44) is not a significant marker in the SP cells in our study. However, several studies indicate that the presence of the ABCG2/ BCRP1 transporter is highly correlated with the SP phenotype in various cells (Hirschmann-Jax et al, 2005) and is downregulated in committed progenitor cells (Scharenberg et al, 2002; Zhou et al, 2002). Therefore, ABCG2/BCRP1 expression is a useful marker for positive selection of several types of cancer stem-like cells (Kim et al, 2002; Scharenberg et al, 2002; Patrawala et al, 2005; AhmedBelkacem et al, 2006). In this study, we show that SP cells express more ABCG2 than non-SP cells, supporting the concept that cancer stem-like cells highly express ABCG2, as seen in other tumour types (Patrawala et al, 2005; Abbott, 2006; Lou and Dean, 2007; Olempska et al, 2007). Verapamil, an ABC transporter inhibitor (Zhou et al, 2001a), which does not significantly inhibit the MDRI transporter (Goodell, 2002), blocked SP cells from excluding the Hoechst dye, indicating the important role of ABCG2/BRCP1 in the SP of ovarian cancer cells. Our in vitro study of cisplatin-resistant ovarian cancer cells (A2780-CR) indicates that SP cells are resistant to chemotherapy and verapamil reverses this chemoresistance. The results suggest that SP cells resist chemotherapy, at least partially because of overexpression of ABCG2.

Stem cell markers NANOG and ABCG2/BCRP1 were colocalised in both SP and non-SP cells, and the specific individual cells in ovarian cancer tissues, as illustrated in our study, make it reasonable to hypothesise that there are cancer stem-like cell niches in ovarian cancer. The stem cell niche is in a specific locale, within the structure in which the microenvironment maintains the 'stemness' of stem cells (Fuchs and Segre, 2000). The cancer stem-like cell niche may be important for maintaining asymmetric divisions and stem-like properties (Iwasaki and Suda, 2009). Interaction with the cancer stem cell niche and tumour microenvironment may lead to tumourigenesis (Howe et al, 1998; Sternlicht et al, 1999).

In summary, we have shown that ovarian cancer cells are heterogenic. The SP cells have the characteristics of cancer stem-like 
cells. They are both highly tumourigenic and chemoresistant. The increased expression of ABCG2/BCRP1 in SP cells is responsible for chemoresistance. These observations have potentially important implications for future therapeutic strategies that target the ovarian cancer stem-like cells.

\section{REFERENCES}

Abbott BL (2006) ABCG2 (BCRP): a cytoprotectant in normal and malignant stem cells. Clin Adv Hematol Oncol 4: 63-72

Ahmed-Belkacem A, Pozza A, Macalou S, Pe Rez-Victoria JM, Boumendjel AN, Di Pietro A (2006) Inhibitors of cancer cell multidrug resistance mediated by breast cancer resistance protein (BCRP/ABCG2). Anticancer Drugs 17: $239-243$

Allikmets R, Schriml L, Hutchinson A, Romano-Spica V, Dean M (1998a) A human placenta-specific ATP-binding cassette gene (ABCP) on chromosome $4 \mathrm{q} 22$ that is involved in multidrug resistance. Cancer Res 58: $5337-5339$

Allikmets R, Schriml LM, Hutchinson A, Romano-Spica V, Dean M (1998b) A human placenta-specific ATP-binding cassette gene (ABCP) on chromosome $4 \mathrm{q} 22$ that is involved in multidrug resistance. Cancer Res 58: $5337-5339$

Alvi AJ, Clayton H, Joshi C, Enver T, Ashworth A, Vivanco MM, Dale TC, Smalley MJ (2003) Functional and molecular characterisation of mammary side population cells. Breast Cancer Res 5: R1-R8

Beachy P, Karhadkar S, Berman D (2004) Tissue repair and stem cell renewal in carcinogenesis. Nature 432: $324-331$

Ben-Porath I, Thomson MW, Carey VJ, Ge R, Bell GW, Regev A, Weinberg RA (2008) An embryonic stem cell-like gene expression signature in poorly differentiated aggressive human tumors. Nat Genet 40: 499-507

Chambers I, Colby D, Robertson M, Nichols J, Lee S, Tweedie S, Smith A (2003) Functional expression cloning of Nanog, a pluripotency sustaining factor in embryonic stem cells. Cell 113: 643-655

Chiba T, Miyagi S, Saraya A, Aoki R, Seki A, Morita Y, Yonemitsu Y, Yokosuka O, Taniguchi H, Nakauchi H, Iwama A (2008) The polycomb gene product BMI1 contributes to the maintenance of tumorinitiating side population cells in hepatocellular carcinoma. Cancer Res 68: $7742-7749$

Dean M, Fojo T, Bates S (2005) Tumour stem cells and drug resistance. Nat Rev Cancer 5: 275-284

Diestra JE, Scheffer GL, Catala I, Maliepaard M, Schellens JH, Scheper RJ, Germa-Lluch JR, Izquierdo MA (2002a) Frequent expression of the multi-drug resistance-associated protein BCRP/MXR/ABCP/ABCG2 in human tumours detected by the BXP-21 monoclonal antibody in paraffin-embedded material. J Pathol 198: 213-219

Diestra JE, Scheffer GL, Catala I, Maliepaard M, Schellens JH, Scheper RJ, Germa-Lluch JR, Izquierdo MA (2002b) Frequent expression of the multi-drug resistance-associated protein BCRP/MXR/ABCP/ABCG2 in human tumours detected by the BXP-21 monoclonal antibody in paraffin-embedded material. J Pathol 198: 213-219

Doyle LA, Ross DD (2003) Multidrug resistance mediated by the breast cancer resistance protein BCRP (ABCG2). Oncogene 22: 7340-7358

Doyle LA, Yang W, Abruzzo LV, Krogmann T, Gao Y, Rishi AK, Ross DD (1998) A multidrug resistance transporter from human MCF-7 breast cancer cells. Proc Natl Acad Sci USA 95: 15665-15670

Dvorak P, Hampl A (2005) Basic fibroblast growth factor and its receptors in human embryonic stem cells. Folia Histochem Cytobiol 43: $203-208$

Feuring-Buske M, Hogge DE (2001) Hoechst 33342 efflux identifies a subpopulation of cytogenetically normal CD34(+)CD38(-) progenitor cells from patients with acute myeloid leukemia. Blood 97: 3882-3889

Fuchs E, Segre JA (2000) Stem cells: a new lease on life. Cell 100: 143-155

Giangreco A, Shen H, Reynolds SD, Stripp BR (2004) Molecular phenotype of airway side population cells. Am J Physiol Lung Cell Mol Physiol 286: L624-L630

Goodell M (2002) Multipotential stem cells and 'side population' cells. Cytotherapy 4: $507-508$

Haraguchi N, Utsunomiya T, Inoue H, Tanaka F, Mimori K, Barnard GF, Mori M (2006) Characterization of a side population of cancer cells from human gastrointestinal system. Stem Cells 24: 506-513

Harris MA, Yang H, Low BE, Mukherje J, Guha A, Bronson RT, Shultz LD, Israel MA, Yun K (2008) Cancer stem cells are enriched in the

\section{ACKNOWLEDGEMENTS}

We thank Renee Reijo Pera for her helpful advice and discussion. This study was supported in part by a grant from the Helene Jaffe Ovarian Cancer Fund. side population cells in a mouse model of glioma. Cancer Res 68: $10051-10059$

Hayward S, Wang Y, Cao M, Hom YK, Zhang B, Grossfeld G, Sudilovsky D, Cunha G (2001) Malignant transformation in a nontumorigenic human prostatic epithelial cell line. Cancer Res 61: 8135-8142

Hirschmann-Jax C, Foster AE, Wulf GG, Goodell MA, Brenner MK (2005) A distinct 'side population' of cells in human tumor cells: implications for tumor biology and therapy. Cell Cycle 4: 203-205

Ho MM, Ng AV, Lam S, Hung JY (2007) Side population in human lung cancer cell lines and tumors is enriched with stem-like cancer cells. Cancer Res 67: 4827-4833

Howe JR, Roth S, Ringold JC, Summers RW, Jarvinen HJ, Sistonen P, Tomlinson IP, Houlston RS, Bevan S, Mitros FA, Stone EM, Aaltonen LA (1998) Mutations in the SMAD4/DPC4 gene in juvenile polyposis. Science 280: $1086-1088$

Iwasaki H, Suda T (2009) Cancer stem cells and their niche. Cancer Sci 100: $1166-1172$

Kim M, Turnquist H, Jackson J, Sgagias M, Yan Y, Gong M, Dean M, Sharp JG, Cowan K (2002) The multidrug resistance transporter ABCG2 (breas cancer resistance protein 1) effluxes Hoechst 33342 and is overexpressed in hematopoietic stem cells. Clin Cancer Res 8: 22-28

Kondo T, Setoguchi T, Taga T (2004a) Persistence of a small subpopulation of cancer stem-like cells in the C6 glioma cell line. Proc Natl Acad Sci USA 101: $781-786$

Kondo T, Setoguchi T, Taga T (2004b) Persistence of a small subpopulation of cancer stem-like cells in the C6 glioma cell line. Proc Natl Acad Sc USA 101: $781-786$

Lou H, Dean M (2007) Targeted therapy for cancer stem cells: the patched pathway and $\mathrm{ABC}$ transporters. Oncogene 26: 1357-1360

Majka SM, Beutz MA, Hagen M, Izzo AA, Voelkel N, Helm KM (2005) Identification of novel resident pulmonary stem cells: form and function of the lung side population. Stem Cells 23: 1073-1081

Mitsui K, Tokuzawa Y, Itoh H, Segawa K, Murakami M, Takahashi K, Maruyama M, Maeda M, Yamanaka S (2003) The homeoprotein Nanog is required for maintenance of pluripotency in mouse epiblast and ES cells. Cell 113: $631-642$

Miyake K, Mickley L, Litman T, Zhan Z, Robey R, Cristensen B, Brangi M, Greenberger L, Dean M, Fojo T, Bates SE (1999) Molecular cloning of cDNAs which are highly overexpressed in mitoxantrone-resistant cells: demonstration of homology to ABC transport genes. Cancer Res 59: $8-13$

Nichols J, Zevnik B, Anastassiadis K, Niwa H, Klewe-Nebenius D, Chambers I, Scholer H, Smith A (1998) Formation of pluripotent stem cells in the mammalian embryo depends on the POU transcription factor Oct4. Cell 95: $379-391$

Nishimura F, Yoshikawa M, Kanda S, Nonaka M, Yokota H, Shiroi A, Nakase H, Hirabayashi H, Ouji Y, Birumachi J, Ishizaka S, Sakaki T (2003) Potential use of embryonic stem cells for the treatment of mouse parkinsonian models: improved behavior by transplantation of in vitro differentiated dopaminergic neurons from embryonic stem cells. Stem Cells 21: $171-180$

Olempska M, Eisenach PA, Ammerpohl O, Ungefroren H, Fandrich F, Kalthoff H (2007) Detection of tumor stem cell markers in pancreatic carcinoma cell lines. Hepatobiliary Pancreat Dis Int 6: $92-97$

Patrawala L, Calhoun T, Schneider-Broussard R, Zhou J, Claypool K, Tang DG (2005) Side population is enriched in tumorigenic, stem-like cancer cells, whereas ABCG2+ and ABCG2- cancer cells are similarly tumorigenic. Cancer Res 65: 6207-6219

Reya T, Morrison SJ, Clarke MF, Weissman IL (2001) Stem cells, cancer, and cancer stem cells. Nature 414: 105-111

Sales KM, Winslet MC, Seifalian AM (2007) Stem cells and cancer: an overview. Stem Cell Rev 3: 249-255

Scharenberg CW, Harkey MA, Torok-Storb B (2002) The ABCG2 transporter is an efficient Hoechst 33342 efflux pump and is 
preferentially expressed by immature human hematopoietic progenitors. Blood 99: 507-512

Seigel GM, Campbell LM, Narayan M, Gonzalez-Fernandez F (2005) Cancer stem cell characteristics in retinoblastoma. Mol Vis 11: 729-737

Steiniger SC, Coppinger JA, Kruger JA, Yates 3rd J, Janda KD (2008) Quantitative mass spectrometry identifies drug targets in cancer stem cell-containing side population. Stem Cells 26: 3037-3046

Sternlicht MD, Lochter A, Sympson CJ, Huey B, Rougier JP, Gray JW, Pinkel D, Bissell MJ, Werb Z (1999) The stromal proteinase MMP3/ stromelysin-1 promotes mammary carcinogenesis. Cell 98: 137-146

Szotek P, Pieretti-Vanmarcke R, Masiakos P, Dinulescu D, Connolly D, Foster R, Dombkowski D, Preffer F, MacLaughlin D, Donahoe P (2006) Ovarian cancer side population defines cells with stem cell-like characteristics and Mullerian inhibiting substance responsiveness. Proc Natl Acad Sci USA 103: 11154-11159

Uchida N, Leung FY, Eaves CJ (2002) Liver and marrow of adult mdr-1a/ $1 \mathrm{~b}(-/-)$ mice show normal generation, function, and multi-tissue trafficking of primitive hematopoietic cells. Exp Hematol 30: 862-869

Wang J, Guo LP, Chen LZ, Zeng YX, Lu SH (2007) Identification of cancer stem cell-like side population cells in human nasopharyngeal carcinoma cell line. Cancer Res 67: 3716-3724

Wong DJ, Liu H, Ridky TW, Cassarino D, Segal E, Chang HY (2008) Module map of stem cell genes guides creation of epithelial cancer stem cells. Cell Stem Cell 2: $333-344$
Wu C, Wei Q, Utomo V, Nadesan P, Whetstone $\mathrm{H}$, Kandel $\mathrm{R}$, Wunder JS, Alman BA (2007) Side population cells isolated from mesenchymal neoplasms have tumor initiating potential. Cancer Res 67: $8216-8222$

Wulf GG, Wang RY, Kuehnle I, Weidner D, Marini F, Brenner MK, Andreeff M, Goodell MA (2001) A leukemic stem cell with intrinsic drug efflux capacity in acute myeloid leukemia. Blood 98: 1166-1173

Yano S, Ito Y, Fujimoto M, Hamazaki TS, Tamaki K, Okochi H (2005) Characterization and localization of side population cells in mouse skin. Stem Cells 23: 834-841

Zhou S, Morris JJ, Barnes Y, Lan L, Schuetz JD, Sorrentino BP (2002) Bcrp1 gene expression is required for normal numbers of side population stem cells in mice, and confers relative protection to mitoxantrone in hematopoietic cells in vivo. Proc Natl Acad Sci USA 99: 12339-12344

Zhou S, Schuetz JD, Bunting KD, Colapietro AM, Sampath J, Morris JJ, Lagutina I, Grosveld GC, Osawa M, Nakauchi H, Sorrentino BP (2001a) The $A B C$ transporter Bcrp1/ABCG2 is expressed in a wide variety of stem cells and is a molecular determinant of the side-population phenotype. Nat Med 7: $1028-1034$

Zhou S, Schuetz JD, Bunting KD, Colapietro AM, Sampath J, Morris JJ, Lagutina I, Grosveld GC, Osawa M, Nakauchi H, Sorrentino BP (2001b) The $\mathrm{ABC}$ transporter Bcrp1/ABCG2 is expressed in a wide variety of stem cells and is a molecular determinant of the side-population phenotype. Nat Med 7: $1028-1034$ 